\title{
The Application of Three-stage Command and Control Organizational Design Method in Emergency Communications Support
}

\author{
Jie Fu, Wenjing Shao, Xuejun Ren, Jisheng Zhu \\ Engineering University of the Chinese people's armed police force, Xi'an 710086, China
}

Keywords: three-stage method, command and control organization, emergency communications support, structural design.

\begin{abstract}
Reasonable and effective command structure is a key element of emergency communications support in special conditions. Through describing two typical problems existing in present emergency communications support, this paper proposes the introduction of command and control organizational theory to solve problems, and takes the communications support in an earthquake relief as the example, and applies three-stage command and control organizational design method to design the communications command and control structure .It proves in theory that this method has good prospects in emergency communications support and provides new ideas for solving the support issues of communications under special conditions.
\end{abstract}

\section{Introduction}

At present, the emergency communications support system has gradually become perfect in our country. Wherein, the majority of communications support is achieved based on a public communications network [1]. Thus, in general emergency communications support, the existing communications network is sufficient to ensure effective interconnection, but under special conditions such as large-scale earthquakes, mudslides, etc., a lot of communications infrastructure will be damaged, it is difficult to complete communications support tasks only relying on traditional communications methods. This paper will study and discuss the communications support methods under such special conditions.

There are many areas to be improved in existing emergency communications support [2], and two urgent issues will be taken as examples next:

Emergency communications systems lack effective command structure. In the face of "urgent and difficult" issues, troops are usually deployed and dispatched hastily because of lacking an effective overall estimation on the events. When dealing with major emergencies, collaboration with several communications powers is often involved in (egg: collaboration between police and public communications, collaboration among different branches of military and armed forces, etc.). While the collaboration among different communications departments (units) usually results in confusion in command structure and unreasonable task deployment due to lack of experience and unified command and deployment method, which will affect the efficiency of the communications support accordingly.

Unreasonable distribution of emergency communications support forces. The communications facilities in different regions are not necessarily all the same due to different city functions and economic levels. It is difficult for people to predict the time, site and extent of damage of sudden disasters such as earthquakes, landslides and other natural disasters, which also brings great difficulty to communications support work. Taking the earthquake taken place in Wenchuan in 2008 as the example, the original communications support work was extremely difficult, and equipment rationing and personnel deployment was not easy too. Communications equipment was surplus in some regions, while was in short supply in some other areas. It extended the task completion time and affected information transfer. However, time was related to the lives of people during the disaster relief, which indicates how important it is to improve the efficiency of emergency communications support. 
These issues reflects that the existing communications command structure is irrational, which is also the blind spot of emergency communications support under current special conditions. Command and control organizational theory is to optimize the internal resource allocation, task planning, and command collaboration reasonably against the problems existing in organizational structure, so as to improve the overall operational effectiveness [3]. Command and control organization is one of the types of organizations, which is usually applied to complex battlefield and armed force organizations. It deploys resource and armed force reasonably, and thus further improves organizational effectiveness. It has a good application prospect to apply the theory of command and control organization to solve the difficulties in emergency communications support under special conditions, and to realize the modular support method of "plug and play".

\section{Basic Theory}

Command and control organization refers to the orderly activities and the corresponding coordination structural relationship formed by each entity according to the requirements of the mission objectives.[4] Command and control organizational design refers to establishing an effective task process and the matching organizational structure based on the analysis of specific organizational environment and combination with the existing constraints, so as to ensure the completion of organizational tasks.

The existing design methods for command and control organizations include: the design method based on three stages, expanded three-stage design method, the design method based on granular computing, and the organizational design method based on group technology and nested genetic algorithm [5]. Currently, researches on command and control organizational design method based on three-stage are relatively mature, and this method is also the most typical and basic design method. Don sheng Yang has described this method in detail in reference [6]. This paper will select this method for analysis and application. The design process of three-stage method is as shown in Figure 1:

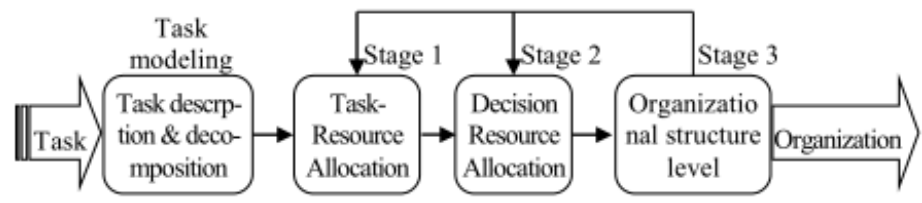

Fig.1: Design Process of Three-stage Method

\section{Case Study}

The communications security in an earthquake relief will be taken as the example next, and the three-stage design method for command and control organization is applied for analysis.

The following definition is made according to the actual situation:

Mission: To achieve effective communications in disaster area.

Elements: Task $(\mathrm{T})$ is the specific objectives of the general mission at different stages; communication power $(\mathrm{P})$ refers to a group or a team responsible for completing specific tasks of communications support. Fourteen communications groups are set in this case; command units (DM) are responsible for the scheduling and deployment of respective communications power; resources: including communications equipment (6 types are set) and so on.

Three stages of structural design:

Planning stage of communications support mission;

Clustering stage of communications power (the determination of the attribution relationship from P to DM;

Command and collaborative structural design stage among command units.

\section{Task planning}

Considering the specific mission environment and changes, the general mission is broken down into 18 tasks, and the order relationship among tasks are as shown in Figure 2. 


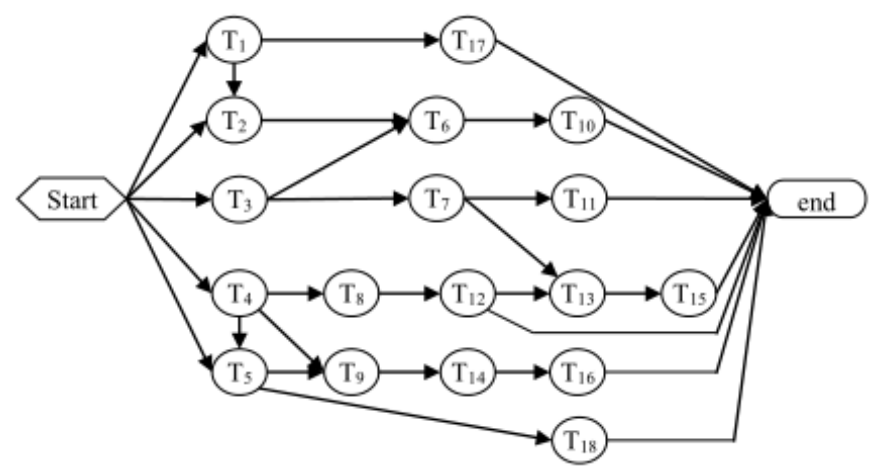

Fig.2: Task Flow Chart

\section{Clustering of Communication power.}

To streamline the number of emergency communications command units (DM) ultimately through effective communications power clustering (merge), and to reduce the work load of command units, so as to improve command efficiency [7]. The mathematical model is built as follows:

$$
\left\{\begin{array}{l}
\min _{S . t} C \beta \\
\sum_{\mathrm{m}=1}^{\mathrm{D}} \mathrm{x}_{\mathrm{mj}}=1 \\
\mathrm{y}_{\mathrm{nmi}} \geq \omega_{\mathrm{ji}} \cdot \mathrm{x}_{\mathrm{mj}} ; \mathrm{y}_{\mathrm{nmi}} \geq \omega_{\mathrm{ji}} \cdot \mathrm{x}_{\mathrm{mj}} \\
\mathrm{u}_{\mathrm{mi}}=\omega_{\mathrm{ji}} \cdot \mathrm{x}_{\mathrm{mj}} \\
\mathrm{y}_{\mathrm{nmi}}=\mathrm{u}_{\mathrm{ni}}+\mathrm{u}_{\mathrm{mi}}-1 \\
\sum_{\mathrm{i}=1}^{\mathrm{N}} \mathrm{u}_{\mathrm{ni}} \leq B^{T} ; \sum_{\mathrm{j}=1}^{\mathrm{K}} \mathrm{x}_{\mathrm{nj}} \leq B^{\prime} ; \sum_{\mathrm{m}=1, \mathrm{~m} \neq \mathrm{n}}^{\mathrm{D}} \sum_{\mathrm{i}=1}^{\mathrm{N}} \min \left(\mathrm{u}_{\mathrm{mi}}, \mathrm{u}_{\mathrm{ni}}\right) \leq B^{E} \\
C \beta \geq W^{I} \sum_{\mathrm{j}=1}^{\mathrm{K}} \mathrm{x}_{\mathrm{nj}}+W^{E} \cdot \sum_{\mathrm{m}=1, \mathrm{~m} \neq \mathrm{n} \mathrm{i}=1}^{\mathrm{D}} \sum_{\mathrm{i}}^{\mathrm{N}} \min \left(\mathrm{u}_{\mathrm{mi}}, \mathrm{u}_{\mathrm{ni}}\right) \\
\mathrm{i}=1, \ldots, \mathrm{N} ; \mathrm{j}=1, \ldots, \mathrm{K} ; \mathrm{m}, \mathrm{n}=1, \ldots, \mathrm{D} ; \mathrm{x}_{\mathrm{nj}}, \omega_{\mathrm{ji}}, \mathrm{y}_{\mathrm{nmi}} \in\{0,1\}
\end{array}\right.
$$

Wherein, the number of emergency communications command posts is $D_{\text {end }}, B^{T}, B^{E}$ and $B^{I}$ as capacity constraints, (set $B^{T}=12, B^{E}=8, B^{I}=6, D_{\text {end }}=5$ ) internal collaboration weights, external collaboration weight.

The algorithm flow chart applied in this paper is as shown in Figure 3.



Fig.3: The Algorithm Process of Communications Power Clustering

During initialization, set the number of command units equal to the number of total communicationns groups. The more the missions that needs the collaboration (i.e., external collaboration) between two commands units are, the smaller their vector clusters are. The calculation formula for the direct external collaboration between the combined communications unit $\mathrm{C}$ and the remaining communications command units is:

$$
D(h, C)=D(h, m)+D(h, n)-\sum_{\mathrm{i}=1}^{\mathrm{N}} \min \left(\min \left(\mathrm{u}_{\mathrm{mi}}, \mathrm{u}_{\mathrm{ni}}\right), \mathrm{u}_{\mathrm{hi}}\right),(h \neq m, n)
$$


If communications groupies involved in tasks $T$, then note $P T(\mathrm{i}, \mathrm{j})=1$, on the contrary, it is 0 . The matrix $P T$ of the allocation relationship between the 14 communications powers and 18 missions is obtained after statistics according to case data.

Allocation Vector $M_{\mathrm{n}}=\left[\mathrm{i}_{\mathrm{n}}, \mathrm{u}_{\mathrm{n} 1}, \ldots, \mathrm{u}_{\mathrm{nN}}\right]$, which represents the number of communications groups under the jurisdiction of communications and command units is the allocation relationship between the communications\& command units and communications support tasks. Screen the combinations of maximum load value and minimum value (possibly multiple sets) by calculating the maximum working load values obtained after the merger of any two communications and command units. As the more the communications support tasks that need the collaborative performance among command units are, the smaller their distance is, and the greater the efficiency brought by merger is[8], therefore, it can be judged based on the minimum dist. anice vector.

Calculation of load value of commander units:

$$
C W(\mathrm{n})=W^{I} \cdot I(\mathrm{n})+W^{E} \cdot E(\mathrm{n})
$$

Vector distance calculation:

$$
\mathrm{d}\left(M_{1}, M_{2}\right)=\mathrm{d}\left(\left[\mathrm{i}_{\mathrm{n}}, \mathrm{u}_{\mathrm{n} 1}, \ldots, \mathrm{u}_{\mathrm{nN}}\right],\left[\mathrm{i}_{\mathrm{m}}, \mathrm{u}_{\mathrm{m} 1}, \ldots, \mathrm{u}_{\mathrm{mN}}\right]\right)
$$

Before the merger, the allocation vector matrix is equation 4 , Select any two communications groups for combination according to the algorithm processes, the allocation vector matrim M1 (P1 and P2 cluster at this time) obtained now is as shown in equation 5 . Followed by analogy, 5 communications command units are eventually obtained through merger.

The collaborative relationship among communications and command units is obtained after calculation:

$$
\begin{aligned}
& M_{0}=\left[\begin{array}{l}
1001000000001010000 \\
1000010000000100100 \\
1000100100010000000 \\
1000100100000000001 \\
1110000000000000000 \\
1100000000100000000 \\
1000000011000001000 \\
1010001000000000000 \\
1000000000100000000 \\
1000000011000001000 \\
1000000000000000110 \\
1000001000000000010 \\
1010000000000000000
\end{array}\right](4), M_{1}=\left[\begin{array}{l}
2001010000000110100 \\
1000100100010000000 \\
1000100100000000001 \\
1110000000000000000 \\
1100000000100000000 \\
1000000011000001000 \\
1010001000000000000 \\
1000000000100000000 \\
1000000011000001000 \\
1000000000000000110 \\
1000001000000000010 \\
1010000000000000000
\end{array}\right] \\
& D(h, C)=[\mathrm{D}(1,4), \mathrm{D}(2,4), \mathrm{D}(3,4), \mathrm{D}(4,4), \mathrm{D}(5,6)]+[\mathrm{D}(1,5), \mathrm{D}(2,5),[\mathrm{D}(3,5), \mathrm{D}(5,5), \mathrm{D}(5,6)]- \\
& =[1,0,0,0,0]+[1,0,0,0,0]-[0,0,0,0,0]=[2,0,0,0,0] \\
& \mathrm{I}(\mathrm{n})=[\mathrm{I}(1), \mathrm{I}(2), \mathrm{I}(3), \mathrm{I}(4), \mathrm{I}(5)]=[\mathrm{PI}(1), \mathrm{PI}(2), \mathrm{PI}(3), \mathrm{PI}(4)+\mathrm{PI}(5), \mathrm{PI}(6)]=[5,4,1,2,1] \\
& \mathrm{E}(\mathrm{n})=[\mathrm{e} 1, \mathrm{e} 2, \mathrm{e} 3, \mathrm{e} 4, \mathrm{e} 5]=[7,8,3,2,2]
\end{aligned}
$$

The final communication power dendrogram is obtained finally after drawing the above results into the diagram 4:

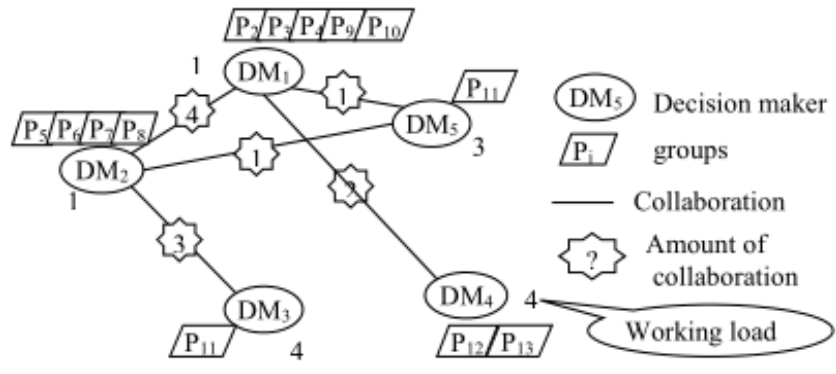

Fig.4: Communication power dendrogram 


\section{Hierarchy Design of Command Unit}

The command and collaborative relationship network among command units is obtained eventually through analysing and calculating the results in Figure 4 with decision-generation algorithm (reference 9) and disconnecting the existing loops. As the case is simple, the specific process will not be elaborated here. The final hierarchy diagram is obtained which is as shown in Figure 5 through disconnecting the link between $\mathrm{DM}_{1}$ and $\mathrm{DM}_{5}$.

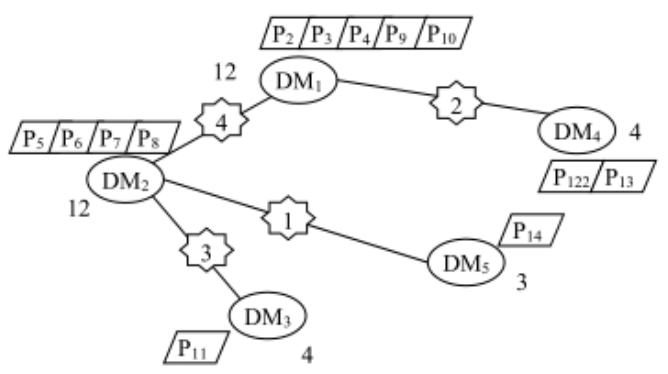

Fig.5: Hierarchy Diagram of Command Unit

\section{Result Analysis}

The command and collaborative relationship among each command unit is cleared, and communications power is also deployed reasonably according to actual demand. The shortcomings of traditional deployment method which mainly depends on experience are basically overcome, quantifying the process of command and control, and improving the efficiency of communications support. While implementing each task, each unit will establish collaborative relationships correspondingly with other units, which improves the utilization of communications unit and equipment resources, reduces the unreasonable distribution, thus ensures that the numbers of communications unit and equipment are reduced while completing the tasks, and improves the efficiency of communications support. The time of communications support task and the specific travel time are determined in the support, which makes the task execution no longer "fuzzy", and time utilization more rational and effective.

\section{Summary and prospects}

This paper has analysed the status quo of emergency communications support under the existing special conditions, and has taken the communications support in an earthquake relief as the example. Three-stage command and control organizational design method is applied in this paper to analyse the mission environment, and to configure and deploy communications power, and reasonable emergency communications support command collaborative network is obtained. The effectiveness of this method is proved theoretically through data analysis, and this method provides new ideas for improving emergency communications support capabilities. However, it is still in the stage of theoretical analysis without fully verification through examples. In the next step, this theory will be studied in-depth and verified with practice.

\section{References}

[1] Jin Yafei, Wu Wen-Jing \& Wang Jing-Li, in extreme cases of emergency communication support scheme analysis. Technology Panorama, 5, p.28-30.May 2013.

[2] Wang Hai-Tao, Status, problems and countermeasures analysis of emergency communication. Digital Communication World, p. 30-33.November 2011.

[3] Shao Wen-Jing, Research on the Application of the Command and Control Organization Theory in Communication Support in Earthquake Relief Work of CAPF, Engineering University of the Chinese people’s armed police force, October 2014.

[4] Yang Dong-Sheng, Zhang Wei-Ming \& Liu Zhong, Effective measure and design of C2 organization. Progress in Natural Science. 15(3), p.349-356, 2005. 
[5] Yao Pei-Yang, Zhang Jie-Yong \& Li Wei, Research progress of adaptively C2 organization. Journal of Air Force Engineering University (Natural Science Edition), 13(2), p.54-56, April, 2012.

[6] Yang Dong-Sheng, Zhang Wei-Ming \& Liu Zhong and Designing of C2 organization, Beijing: National defines industry press, 2010.

[7] Yang Dong-Sheng, Liu Zhong \& Zhang Wei-Ming, Research about Approach to Designing Organization- Three-Phase Approach. Journal of Industrial Engineering, 19(4), p.19-25, 2005.

[8] Yang Dong-Sheng, Zhang Wei-Ming \& Liu Zhong, Descriptions and designing of C2 organizational in battlefields, Systems Engineering Theory and Practice, 5(5), p.83-88, 2005.

[9] Yu Ming, Xiu Bao-Xin, Huang Jin-Cai, Design and analysis of the measure of C2 organizational effectiveness. Fire control \& command control, 5(37), p.110-119, 2012

[10] Records of the Earthquake Relief Work. 